\title{
Impact of the roll out of comprehensive emergency obstetric care on institutional birth rate in rural Nepal
}

Sheela Maru 1,2,3,4 Alex Harsha Bangura ${ }^{5}$, Pooja Mehta ${ }^{2,3}$, Deepak Bista ${ }^{1}$, Lynn Borgatta ${ }^{2,3}$, Sami Pande ${ }^{6}$, David Citrin ${ }^{1,7,8,9}$, Sumesh Khanal ${ }^{10}$, Amrit Banstola ${ }^{11,12}$ and Duncan Maru 1 13,14,15*

\begin{abstract}
Background: Increasing institutional births rates and improving access to comprehensive emergency obstetric care are central strategies for reducing maternal and neonatal deaths globally. While some studies show women consider service availability when determining where to deliver, the dynamics of how and why institutional birth rates change as comprehensive emergency obstetric care availability increases are unclear.

Methods: In this pre-post intervention study, we surveyed two exhaustive samples of postpartum women before and after comprehensive emergency obstetric care implementation at a hospital in rural Nepal. We developed a logistic regression model of institutional birth factors through manual backward selection of all significant covariates within and across periods. Qualitatively, we analyzed birth stories through immersion crystallization.
\end{abstract}

Results: Institutional birth rates increased after comprehensive emergency obstetric care implementation (from 30 to 77\%, OR 7.7) at both hospital (OR 2.5) and low-level facilities (OR 4.6, $p<0.01$ for all). The logistic regression indicated that comprehensive emergency obstetric care availability (OR 5.6), belief that the hospital is the safest birth location (OR 44.8), safety prioritization in decision-making (OR 7.7), and higher income (OR 1.1) predict institutional birth ( $p \leq 0.01$ for all). Qualitative analysis revealed comprehensive emergency obstetric care awareness, increased social expectation for institutional birth, and birth planning as important factors.

Conclusion: Comprehensive emergency obstetric care expansion appears to have generated significant demand for institutional births through increased safety perceptions and birth planning. Increasing comprehensive emergency obstetric care availability increases birth safety, but it may also be a mechanism for increasing the institutional birth rate in areas of under-utilization.

Keywords: Maternal mortality, Institutional birth rate, Global health, Implementation research, Nepal

\section{Background}

The greatest lifetime risk for a mother and her baby occurs during childbirth; over 800 women die from preventable childbirth-related causes every day [1]. More than $40 \%$ of the world's 535,900 annual maternal deaths are related to intrapartum complications, which are

\footnotetext{
* Correspondence: duncan@possiblehealth.org

${ }^{1}$ Possible, Bayalpata Hospital, Sanfebagar-10, Achham, Nepal

${ }^{13}$ Department of Medicine, Division of Global Health Equity, Brigham and

Women's Hospital, 75 Francis Street, Boston, MA, USA

Full list of author information is available at the end of the article
}

closely linked to the world's two million annual intrapartum and neonatal deaths [2, 3]. 99\% of these deaths occur in low- and middle-income countries [1].

Increasing the institutional birth rate (IBR) is a central strategy in reducing mortality, yet several factors continue to challenge progress. Nepal, one of South Asia's most impoverished countries, is a paradigmatic case of these challenges. In 2011, the maternal mortality ratio in Nepal was estimated at 281 per 100,000 , and only $35 \%$ of births took place in a healthcare facility [4]. 
The Three Delays Model offers a useful framework for understanding the barriers to achieving institutional birth: the first delay occurs with care-seeking, the second in arrival at a healthcare facility, and the third in the provision of appropriate care [5]. The first and second delays are often considered demand problems. Maternal age, parity, education, and household wealth have all been positively associated with service usage [6]. These factors suggest that experience with labor, awareness of danger signs, autonomy, and financial support all increase demand for maternal healthcare. Governmentsupported financial incentives and outreach programs have been in place in Nepal since 2009, and are attributed to increased institutional birth [7]. However, rural Nepal is a patriarchal society where a woman often must defer healthcare decisions to her husband or his family members, particularly the mother-in-law [8]. Lack of support from this older generation remains a key barrier to maternal healthcare services utilization [8-11], and may be more important than cost or lack of awareness [9]. While financial, educational, and participatory action-based community mobilization strategies have shown success in improving utilization in Nepal and elsewhere, there is limited evidence that increased demand alone improves maternal and neonatal outcomes [12, 13].

The third delay, the provision of appropriate care, is a supply problem addressed by increasing availability of trained providers and well-equipped facilities critical to improving outcomes [13]. To significantly reduce maternal mortality, the World Health Organization recommends at least four basic emergency obstetric care (BEmOC) facilities and one comprehensive emergency obstetric care (CEmOC) facility per 500,000 people [14]. CEmOC includes cesarean section, blood transfusion services, and sick newborn care in addition to all five signal BEmOC functions (parenteral antibiotics, uterotonics, and anticonvulsants; manual placenta removal; removal of retained products of conception; assisted vaginal delivery; and basic newborn resuscitation) [14]. While evidence for impact of intrapartum interventions and EmOC on maternal outcomes remains inadequate in low-resource settings $[15,16]$, it is estimated that universal CEmOC coverage would avert 519,000 , or $85 \%$ of intrapartum-related neonatal deaths per year [17].

The three delays are interrelated, as decisions about when and where to seek care are limited by available services. Others have found that increasing emergency obstetric services leads to increased institutional birth and that women consider service availability when deciding where to deliver [18-20]. Importantly, a recent quasi-experimental study comparing demand- and supply-side interventions demonstrated that when financial incentive programs were followed by increased access to BEmOC, communities saw the greatest gains in institutional birth, particularly for the most impoverished groups [21]. However, the dynamics of how maternal healthcare-seeking behavior evolves during CEmOC expansion have not been studied. In this study, we explore obstetric healthcare-seeking behavior for women living in the catchment area population of a facility undergoing transition from BEmOC to CEmOC. We examine barriers to care, as understood through the Three Delays Model, prior to and after this transition. Understanding these barriers and factors in women's decisions has important implications for quality improvement, health education, and outreach.

\section{Methods}

We conducted this research in collaboration with the non-profit organization Possible, which operates Bayalpata Hospital as a public-private partnership with the Ministry of Health of Nepal. Bayalpata Hospital provides free care to a catchment area population of approximately 36,000 people in 14 village clusters in Achham, one of the poorer districts in Nepal's hilly Far-Western Development Region [4]. Over the course of the study, the hospital expanded its services from BEmOC to CEmOC. In a district of approximately 260,000 people, there is only one other physician-staffed facility, and six of the area's 14 village clinics (known in Nepal as health posts) were designated as BEmOC facilities during the study.

For this pre- and post-intervention cohort study on the impact of CEmOC expansion on institutional birth in rural Nepal, we surveyed an exhaustive sample of all women less than six weeks postpartum during three month periods before and after CEmOC expansion. The sample included two populations of postpartum women who: (1) delivered in the community (at home or at a clinic) and (2) either delivered or received services for postpartum complications in the hospital. Women presenting to the hospital were identified, consented, and interviewed by nurse-midwives, while women delivering in the community were identified by government community health workers (CHWs, known locally as Female Community Health Volunteers) and interviewed by the hospital's paid CHWs.

All postpartum women within six weeks of birth and living in the catchment area were eligible for participation in the study. Women referred to another facility after arriving at Bayalpata Hospital were later excluded due to difficulty in determining outcomes in this dispersed population. There were no other exclusion criteria. Women received NRs 100 (approximately 1 USD) compensation for participating. Government CHWs received NRs 50 for each woman identified and nursemidwives received NRs 100 for each survey administered. 
Bayalpata CHWs received no additional compensation, as these activities are part of their employment contract.

In addition to demographic questions, we asked the women about their choice of delivery location, their beliefs around safe delivery practices, the factors important in their decision-making process, and their satisfaction with their choice. We elicited factors through openended questioning and later coded them into themes; dummy variables were then used to enumerate the frequency of each factor within and between groups. All other questions were multiple choice.

We coded all quantitative data on paper and manually entered the codes into an excel spreadsheet. Identifiers were not collected. We coded and analyzed the preintervention data separately for a previous study on drivers of institutional birth [22]. After completing the post-intervention surveys, we added the data to a pooled dataset and re-analyzed them using JMP version 11 (SAS Institute Inc., Cary, NC 2013). We conducted bivariate analysis of demographics across periods and factors associated with institutional birth, and within and across periods. We used Fisher's exact test for categorical variables (e.g., caste, parity, delivery location, priority factors), and the Wilcoxon rank-sum test for all continuous variables (e.g., age, income, land, distance, travel cost), as they had non-normal distributions. We determined significance with an alpha-cutoff of 0.05. For the logistic regression analysis, we entered all significant variables in the bivariate analyses (listed in Tables 1 and 2) into the model and refined using manual backward elimination, with an alpha cut-off of 0.05 . Those variables that did not meet the cut-off are not reported in the final model.

To qualitatively assess the impact of CEmOC expansion on institutional birth, we posed a single open-ended question to each participant: "Tell me the story of your birth." The enumerators transcribed responses in shorthand in Nepali and then we translated them into English. Two investigators analyzed responses from the pre- and post-expansion data through immersion crystallization [23]. The social contextual model, which illuminates pathways by which social and contextual factors lead to differing health outcomes or health behaviors, informed the analysis [24]. Based on the model, we categorized factors as modifying or mediating on individual, interpersonal, organizational, community, or societal levels. The modifying factors were those that affected the outcome independently of the intervention pathway. The mediating factors were on the pathway between the intervention and the outcome. We undertook this analysis separately in 2012 and 2014 and compared the results to explore how birth stories changed with the expansion to CEmOC.

\section{Results}

We surveyed 98 and 133 women pre- and post-expansion, respectively, including 21 women living outside the catchment area who delivered at Bayalpata Hospital. Bayalpata CHWs do not follow women outside the catchment area population and thus similar women who delivered at

Table 1 Sample characteristics and demographics

\begin{tabular}{|c|c|c|c|}
\hline Sample demographics & Pre-expansion group (2012) & Post-expansion group (2014) & $P$-values ${ }^{\mathrm{i}, \mathrm{j}}$ \\
\hline Total (n) & 77 & 133 & - \\
\hline Age, median $(\mathrm{IQR})^{\mathrm{i}}$ & $25(21-28)$ & $22(20-26)$ & 0.1 \\
\hline Distance (hours), median (IQR) ${ }^{a, i}$ & $2(1-2)$ & $2(1-2)$ & 0.37 \\
\hline Income, median $(\mathrm{IQR})^{\mathrm{b}, \mathrm{i}}$ & $1000(0-5000)$ & $5000(3000-7000)$ & $<0.01$ \\
\hline Ropani, median $(\mathrm{QQR})^{\mathrm{c}, \mathrm{i}}$ & $5(2-12)$ & $5(2-7)$ & 0.01 \\
\hline Upper caste, $\mathrm{n}(\%)^{\mathrm{d}, \mathrm{j}}$ & $41(53 \%)$ & $80(60 \%)$ & 0.36 \\
\hline Some literacy, n (\%) $)^{e, j}$ & $43(55 \%)$ & $114(86 \%)$ & $<0.01$ \\
\hline Multiparity, n (\% $)^{\mathrm{fj}}$ & $57(74 \%)$ & $83(62 \%)$ & 0.08 \\
\hline ANC visits Adequate, $n(\%)^{g, j}$ & $53(69 \%)$ & $115(86 \%)$ & $<0.01$ \\
\hline Autonomy, n (\%) ${ }^{\mathrm{h}, \mathrm{j}}$ & $25(32 \%)$ & $65(49 \%)$ & 0.02 \\
\hline
\end{tabular}

${ }^{a}$ Distance is defined as the number of hours required to travel from the respondent's home to the hospital using the fastest mode of transport available to the respondent

Income measured in Nepali Rupees (NRs); regression analysis was done per 1,000 NRs

${ }^{c}$ Ropani is a local measure of farming land in Nepal equal to $508.72 \mathrm{~m} 2$

dUpper caste is any non-Dalit (untouchable) caste

e Some literacy is defined as either completion of elementary schooling or any self-reported ability to read in Nepali or English

${ }^{f}$ Multiparity is the number of respondents who had more than one previous birth

${ }^{9}$ Adequacy of ANC visits is defined in accordance with the Nepali government's minimum of four visits

homen who reported themselves as either the primary or the joint decision-maker were coded as "Autonomous" compared to women who reported their husbands, fathers or mothers-in-law as the primary decision-makers

i $P$-values for non-normal continuous variables were calculated using Wilcoxon rank-sum test

j $P$-values for categorical variables were calculated using Fisher's exact test 
Table 2 Factors of institutional births, compared across time and between birth location in each time period

\begin{tabular}{|c|c|c|c|c|c|c|c|c|c|}
\hline \multirow{2}{*}{$\begin{array}{l}\text { Institutional Birth } \\
\text { Factors }\end{array}$} & \multicolumn{3}{|c|}{2012 n (\% of yes respondents) } & \multicolumn{3}{|c|}{2014 n (\% of yes respondents) } & \multicolumn{3}{|c|}{ Total n (\% all respondents) } \\
\hline & $\begin{array}{l}\text { Home } \\
(n=54)\end{array}$ & $\begin{array}{l}\text { Facility } \\
(n=23)\end{array}$ & $P$-values ${ }^{a}$ & $\begin{array}{l}\text { Home } \\
(n=31)\end{array}$ & $\begin{array}{l}\text { Facility } \\
(n=102)\end{array}$ & $P$-values ${ }^{a}$ & $\begin{array}{l}2012 \\
(n=77)\end{array}$ & $\begin{array}{l}2014 \\
(n=133)\end{array}$ & $P$-values ${ }^{a}$ \\
\hline Hospital is safer & $47(61.0)$ & $22(28.6)$ & 0.42 & $27(20.9)$ & $102(79.1)$ & $<0.01$ & 69 (89.6) & $129(97.0)$ & 0.03 \\
\hline Priority on safety & $6(23.1)$ & $20(76.9)$ & $<0.01$ & $18(22.0)$ & $64(78.0)$ & 0.68 & $26(33.8)$ & $82(61.7)$ & 0.01 \\
\hline Priority on cost & $2(100)$ & $0(0)$ & $>0.99$ & $5(12.5)$ & $35(87.5)$ & 0.07 & $2(2.6)$ & $40(30.1)$ & $<0.01$ \\
\hline Priority on distance & $32(91.4)$ & $3(8.6)$ & $<0.01$ & $9(29.0)$ & $24(72.7)$ & 0.63 & $35(45.5)$ & $33(24.8)$ & $<0.01$ \\
\hline Priority on CEmOC & $1(100)$ & $0(0)$ & $>0.99$ & $4(8.9)$ & $41(91.1)$ & $<0.01$ & $1(1.3)$ & $45(33.8)$ & $<0.01$ \\
\hline $\begin{array}{l}\text { Knowledge of CEmOC } \\
\text { availability }\end{array}$ & $10(76.9)$ & $3(23.1)$ & $>0.99$ & $3(3.2)$ & $90(96.8)$ & $<0.01$ & $13(20.3)$ & $93(86.9)$ & $<0.01$ \\
\hline
\end{tabular}

${ }^{\mathrm{a} P} P$-values are calculated from Fisher's exact tests

home were not a part of the sample. To reduce bias, we excluded these 21 out-of-catchment women from the final analysis, resulting in 77 pre-expansion and 133 postexpansion respondents.

In 2012, 21 women reported delivering in the hospital, 2 in a village clinic (lower level facility), and 54 at home. In 2014, 79 women reported delivering in the hospital, 23 in a village clinic, and 31 at home. In order to verify our exhaustive sampling, we retrospectively reviewed hospital records. There were 30 eligible hospital births documented during the months of data collection in 2012 and 85 in 2014. While we do not have a goldstandard comparator for village clinic and home deliveries, these data suggest we achieved $70 \%$ survey coverage in the pre-expansion and $93 \%$ survey coverage in the post-expansion hospital delivery groups.

Monthly income, literacy, antenatal visit completion, and autonomy in delivery-care decisions were all significantly higher for the post-expansion group, but the groups were similar in terms of age, distance to facility, median land ownership, parity, and caste as shown in Table 1.

Institutional birth increased significantly after $\mathrm{CEmOC}$ implementation, from 30\% (CI 21-41\%) to 77\% (CI 69$83 \%$ ) at both hospital (27 to 59\%) and village clinic levels (3 to $17 \%$ ) as shown in Fig. 1.

We report the results of the bivariate analysis of significant factors in Table 2. The number of women who believed the hospital is the safest delivery location and who prioritized safety in decision-making increased post-expansion. Prioritization of distance decreased, while prioritization of cost increased post-expansion. Median travel cost to the facility marginally decreased (300 to $260 \mathrm{NRs}, p<0.01$ ) and slightly more women received the government-sponsored incentive payment (91\% versus $100 \%, p=0.03$ ). Finally, post-expansion, more women reported prior knowledge of service availability and prioritization of services.

The logistic regression indicated exposure to CEmOC availability, the belief that the hospital is the safest delivery location, safety prioritization in decisionmaking, and higher monthly income predict institutional birth $(A U C=0.83)$. There was a significant interaction of safety prioritization and time, such that pre-expansion women who prioritized safety were seven times more likely to deliver in an institution than those who did not, as shown in Table 3.

Satisfaction with birth experiences increased (87 to $99 \%, p<0.01)$. Women delivering in an institution postexpansion were more likely to be satisfied with their delivery care (OR 13, $p=0.04$ ). There was no significant difference in perceived adequacy of staff, supplies, or facilities in the pre- and post-expansion institutional birth groups.

In comparing the pre- and post-expansion birth stories, there were several notable differences as demonstrated in Table 4. Mediating factors on an individual and interpersonal level, such as perceptions of safety, knowledge of services, and the awareness of a potential need for services were increasingly common postexpansion. Some explained motivation for hospital births in the context of prior or current birth complications, demonstrating a perceived risk of home birth that could be addressed in the hospital due to CEmOC. One woman noted, "I knew that this hospital provided a complete set of services, just like other hospitals." Women who gave birth in the village clinic often did so as a secondary option, but largely reported positive impressions of safety and quality.

We identified referrals, birth planning, and preparedness as organizational- and societal-level factors driving institutional birth. One woman said, "per the suggestion of the $[\mathrm{CHW}] . .$. I also decided to deliver with skilled healthcare personnel." More women in the postexpansion group mentioned detailed birth planning involving the hospital or village clinic. As one woman described, "I completed four antenatal care visits. I had also arranged for money and clothes. When the labour pain started, we called the jeep [for the hospital]." Preexpansion, very few women expressed similar birth 


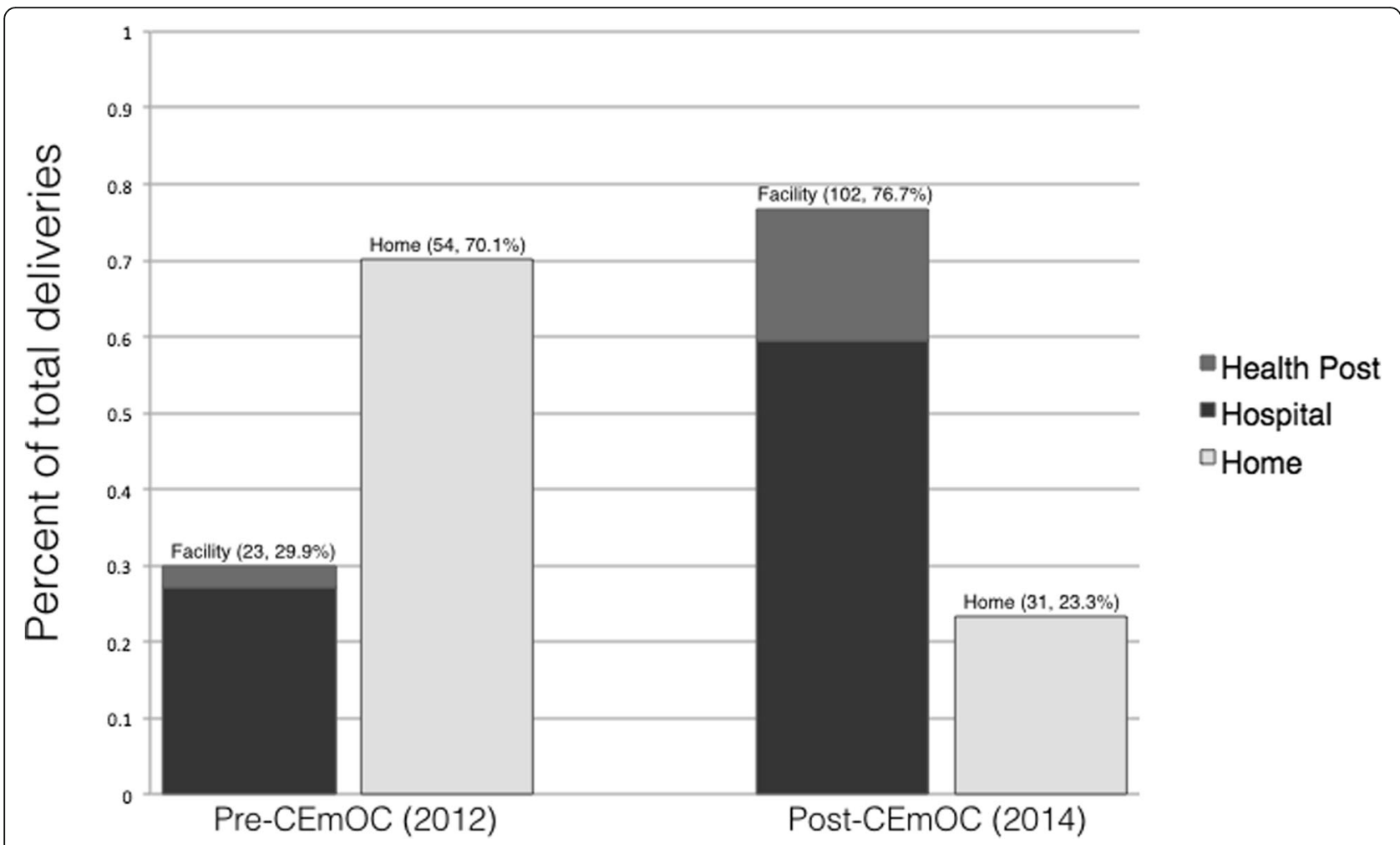

Fig. 1 Proportion of facility (including health post and hospital births) and home births before and after roll-out of Comprehensive Emergency Obstetric Care at Bayalpata Hospital. Abbreviations: CEmOC, Comprehensive Emergency Obstetric Care

plans. There were three referrals in the pre-expansion group from the hospital to higher-level facilities. All led to non-institutional births because of difficulties and delays with transportation. After CEmOC implementation, there were no similar referrals. Five women had cesarean deliveries and one woman received a blood transfusion.

Modifying factors at the individual and interpersonal level, as shown in Fig. 2, included family (particularly mother-in-law) and partner support, access to financial resources, means of transport to an institutional setting, and gendered work responsibilities. Many women relayed the importance of family and partner support; its absence highlighted the lack of autonomy that many experience. In both years, women who failed to have an institutional birth reported challenges finding travel assistance, often due to inadequate family or community support and planning. Nonetheless, the government-provided financial incentive for travel was a societal-level modifying factor that motivated women to have an institutional birth in both time periods.

\section{Discussion}

The IBR at both the hospital and village clinics more than doubled after CEmOC expansion. To understand this dramatic change, we used logistic regression to assess the importance of CEmOC availability, beliefs about hospital safety, factors reported as important to women's

Table 3 Results of a logistic regression model for institutional birth

\begin{tabular}{|c|c|c|c|c|c|}
\hline Regression term & Estimate & Std. error & Odds ratio & $95 \% \mathrm{Cl}$ & $P$-value \\
\hline CEmOC availability & 0.86 & 0.24 & 5.6 & $2.2-15$ & 0.01 \\
\hline Income (per 1000 NRs) & 0.07 & 0.03 & 1.1 & $1.0-1.1$ & 0.01 \\
\hline Hospital Safety & 1.9 & 0.69 & 45 & $4.8-1300$ & $<0.01$ \\
\hline Safety priority & 1.02 & 0.24 & 7.7 & $3.2-21$ & $<0.01$ \\
\hline CEmOC availability-Safety priority ${ }^{a}$ & -1.06 & 0.24 & 0.1 & & $<0.01$ \\
\hline Safety priority pre-intervention & 1.02 & & 7.7 & & \\
\hline Safety priority post-intervention & -0.04 & & 0.9 & & \\
\hline
\end{tabular}

${ }^{a}$ Interaction term represents the effect of reporting safety as a priority on the likelihood of institutional birth in each time period 
Table 4 Examples of women's birth stories from 2012 and 2014

\begin{tabular}{|c|c|c|}
\hline & 2012 & 2014 \\
\hline Home & $\begin{array}{l}\text { "All day I worked on the farm. At } 7 \text { pm, labor pain started. } \\
\text { At } 12 \text { am, female baby was born at home." } \\
\text { "- } \\
\text { "I didn't know about the hospital and I don't have anyone } \\
\text { who could carry me to the hospital." } \\
\text { "- } \\
\text { "I planned to go to the hospital to give birth. I knew about } \\
\text { the } 1000 \text { NRs [government incentive]. My home condition }\end{array}$ & $\begin{array}{l}\text { "I had } 4 \text { ANC checks - one at hospital and rest } 3 \text { at the HP. I had planned } \\
\text { to deliver at the HP, but my labor started suddenly and by the time people } \\
\text { had gathered to take me to the HP, I had already delivered. I am planning } \\
\text { to deliver my next baby at the hospital though." } \\
\text { "- } \\
\text { "I had planned to deliver at the hospital and I was on my way as well. } \\
\text { But I delivered mid-way. There wasn't any safe birth kit, no clean cloths. } \\
\text { So, it was very difficult." }\end{array}$ \\
\hline
\end{tabular}
is very bad and I have no support for people to bring me to the hospital. I had a long course of labor pain, but couldn't find anyone to carry me to the hospital, so I delivered at home."

Facility "I started having labor pain and since the hospital is nearby I walked to the hospital and had my baby safely delivered."

"A mother of two wanted to give birth in the hospital because they were close by and because the mother thought it would be safer. Her previous children were born at home. Belly pain started late into the night and the family called the ambulance. Unfortunately, the ambulance was not working so it was not able to pick her up. The family got together and found a stretcher. She was carried on a stretcher during the night, one hour away from the hospital. She delivered in the early morning at Bayalpata Hospital." [as translated]

"I wanted to go to $\mathrm{BH}$ to deliver, but there was nobody to help me to the hospital [so I went to the village clinic instead]. My husband is in India and there is just an old mother-in-law at home. But I did complete all four ANCs, took my iron tabs regularly and also the Immunization."

"This was my first pregnancy... I completed 4 ANCs. I had also arranged for money and cloths. When the labour pain started, we called the jeep. I delivered normally in the hospital. I am very happy."

"I had thought that if I can't deliver normally then I would deliver via operation. But I could deliver normally, so I am very happy. I also got very good service in the hospital. Because I didn't have enough money I couldn't afford to travel to the hospital. But here I was given [government incentive] money for return travel."

Abbreviations: ANC Antenatal care, HP Health post (local term for village clinic), NRs Nepalese Rupees, BH Bayalpata Hospital

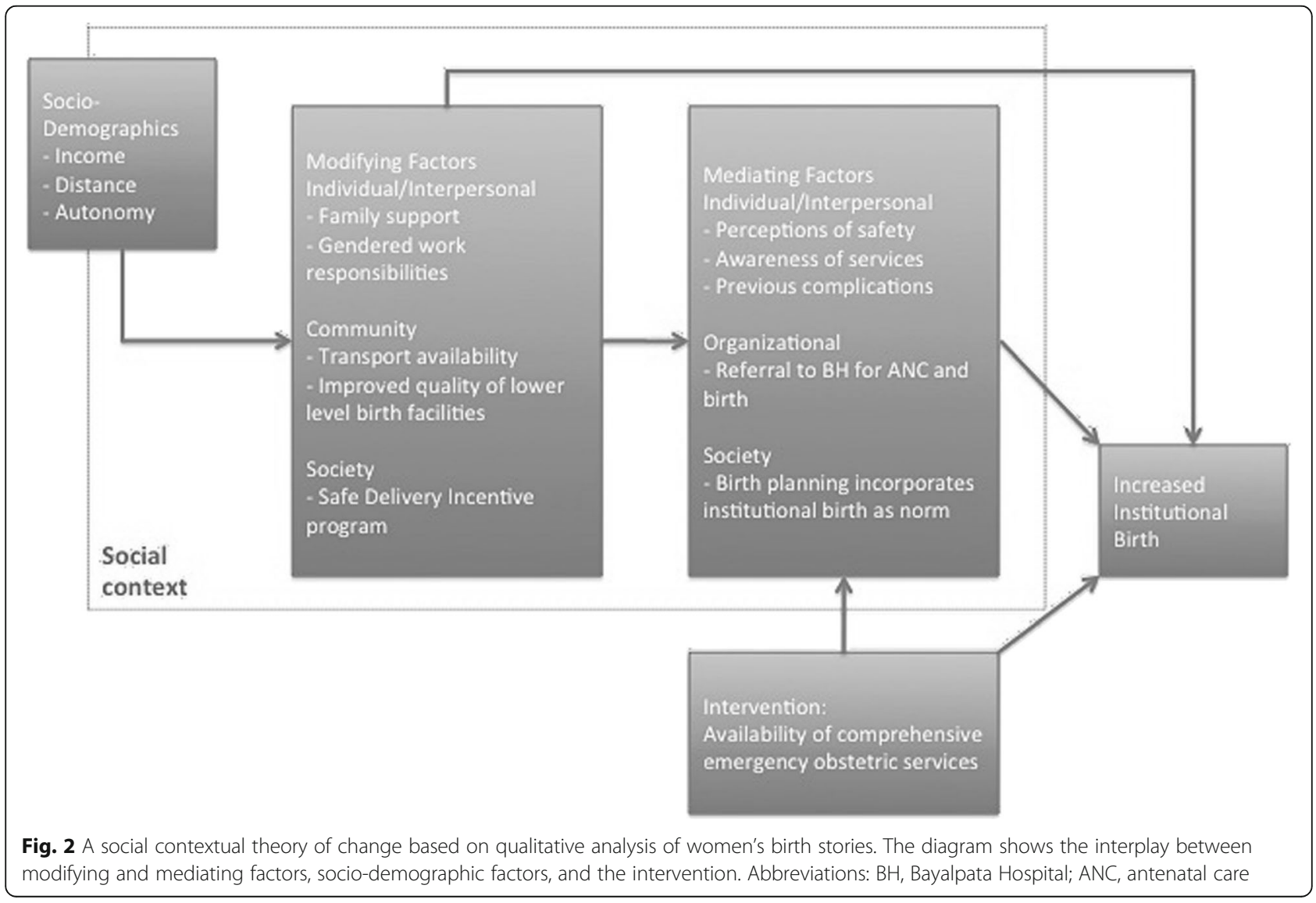


decisions on delivery location, and knowledge of available services. We also assessed significant changes in income, land ownership, literacy, antenatal care coverage, and locus of decision-making power (self vs. other).

The final regression model indicated that institutional birth was associated with CEmOC service availability, belief in hospital safety, increased income, and prioritization of safety. The overall increase in proportion of women who prioritize safety post-expansion (in both institution and home birth groups) suggests that decision-making factors are sensitive to changes in emergency obstetric services, however prioritization of safety was only significant between institution and home birth groups in the preCEmOC period. Awareness of services also increased, though it did not meet significance criteria for inclusion in the final model. These trends suggest an increase in the perceived value of institutional birth driven by improved access to CEmOC.

The substantial increase in institutional birth seen in our quantitative analysis can be partly understood by the mediating social and contextual factors identified in our qualitative analysis. An increased perception of the hospital as a safer and more desirable place to give birth was notable in post-expansion birth stories. Village clinic deliveries were less desirable alternatives to hospital deliveries but were often more achievable due to travel constraints and viewed favorably by women who experienced them. This effect suggests broader normalization of institutional delivery and greater trust in the healthcare system. Normalization of institutional birth may explain why perception of hospital safety strongly predicts institutional birth in both time periods while prioritization of safety only did so prior to CEmOC expansion.

The modifying social and contextual factors identified are those not related to service expansion. The importance of increased income in the quantitative analysis suggests economic development is a modifying factor. In the qualitative analysis, however, we found social support and autonomy more important in both time periods, especially in the context of the pre-existing government incentive. Increasing social support for institutional birth, advancing gender equality, further developing transportation resources, and encouraging birth preparedness should be key targets of future interventions to encourage institutional birth and decrease maternal mortality in this setting.

There are several limitations to our study that encourage caution in generalizing conclusions about the effect of implementing CEmOC on institutional birth in rural areas. It is important to note, given the broad acceptance that cesarean deliveries and blood transfusions save lives, that a randomized, controlled trial would be unethical. As such, questions must be answered via non- randomized approaches. Given the observational pre/ post design, the effect of prior trends is not accounted for in the analysis. Increased income may represent a secular "development" trend not fully captured by sociodemographic data. Village clinic quality improvements were not assessed and remain possible confounders given the increase in births at those facilities. We attempted to address these issues through qualitative analysis of individual birth stories.

While we aimed to reach all eligible postpartum women, the sampling technique introduces possible bias because women who delivered at home may have been more difficult to identify or reach by CHWs and we have no gold-standard comparator to validate our coverage. However, our total sample is approximately 70 and $98 \%$ of the 110 and 135 deliveries (in 2012 and 2014, respectively) expected by Nepal's 2013 crude birth rates. These estimates suggest our 70 and $93 \%$ coverage of hospital deliveries is unlikely to have systematically undersampled home deliveries. Our IBRs correlate well with the 35\% IBR reported for the region in Nepal's 2011 Demographic and Health Survey [25], and the 83\% IBR reported in a 2014 census conducted in the hospital's catchment area population [26]. The use of CHWs and nurse midwives as enumerators also increases bias in self-reported perceptions of and preferences for institutional birth. We assume that sampling and self-report biases would be equal across time periods and thus less likely to affect questions of change in institutional birth.

\section{Conclusion}

While demand-generating activities have proven critical to increased IBRs [13], we demonstrate that CEmOC expansion can drive significant demand for institutional births in an impoverished community with previously low access. After CEmOC expansion, women appeared to perceive more benefits of institutional birth and incorporate it into a normative framework that encouraged planning for the extra costs and contingencies required to achieve it. This effect also cascaded down to BEmOC village clinics, with women exhibiting greater trust in the healthcare system overall.

We believe that the demand-generating capacity of CEmOC services should thus be taken into account when considering allocation of maternal and neonatal healthcare resources. These findings support greater expansion of CEmOC services in rural underserved areas even when IBRs are low, as the services are likely to increase both utilization and safety. By increasing demand for institutional births while also making those births safer, surgical obstetric expansion likely has a greater impact on childbirth-related mortality than demandgenerating or BEmOC expansion approaches alone. 


\section{Abbreviations}

ANC: Antenatal Care; AUC: Area Under Curve; BEmOC: Basic Emergency Obstetric Care; BH: Bayalpata Hospital; CEmOC: Comprehensive Emergency Obstetric Care; CHW: Community Health Worker; Cl: Confidence Interval; FCHV: Female Community Health Volunteer; IBR: Institutional Birth Rate; IQR: Interquartile Range; NRs: Nepalese Rupees; OR: Odds Ratio; USD: United States Dollars

\section{Acknowledgments}

We would like to express our appreciation to the Government of Nepal, Ministry of Health for their continued efforts to improve the institutional birth rate in rural Nepal, and to both the Nepal Health Research Council and the Brigham and Women's Hospital Institutional Review Board for granting ethical approval.

\section{Funding}

The Mary Horrigan Connors Center for Women's Health \& Gender Biology at Brigham and Women's Hospital and the Harvard Humanitarian Initiative provided funding for Dr. Sheela Maru's work with this study through a Global Women's Health Fellowship. The Center for Primary Care at Harvard Medical School provided funding for Dr. Alex Harsha Bangura's work with this study. Dr. Duncan Maru received support from the Office of the Director National Institutes of Health under an Early Independence Award, number DP5OD019894. The Eunice Kennedy Shriver National Institute Of Child Health \& Human Development (NICHD) and the National Institute Of Dental \& Craniofacial Research (NIDCR) provided support for this award. The funders played no role in research design, data collection, data analysis, manuscript write-up, or decision to publish.

\section{Availability of data and materials}

De-identified data are available at the Healthcare System Design Group's (Possible's Implementation Research Team) website (http://hsdg.partners. org/). We do not provide full transcriptions of the qualitative data. These transcripts contain quotes and identifiable information that could compromise the identity of participants. Data may also be requested by emailing: research@possiblehealth.org.

\section{Authors' contributions}

Contributed to research design: SM, PM, LB, DM. Collected the data: SM, DB, DC, SP, SK, AB. Analyzed the data: SM, AHB, PM, DC, DM. Contributed to writing the manuscript: SM, AHB, DM. Reviewed and approved the manuscript: all authors. ICMJE criteria for authorship met: all authors. All authors read and approved the final manuscript.

\section{Competing interests}

SM and DM work in partnership with a nonprofit healthcare company (Possible) that delivers free healthcare in rural Nepal using funds from the Government of Nepal and other public, philanthropic, and private foundation sources. DB and DC are employed by Possible. At the time of the research study, AHB worked in partnership with and SP, SK, and AB were employed by Possible. SM, PM, and LB are employed at an academic medical center (Boston Medical Center) that receives public sector research funding, as well as revenue through private sector fee-for-service medical transactions and private foundation grants. SM, PM, and LB are faculty members at a private university (Boston University School of Medicine). SM is a research fellow at and DM is employed by an academic medical center (Brigham and Women's Hospital) that receives public sector research funding, as well as revenue through private sector fee-for-service medical transactions and private foundation grants. AHB is a resident at a public hospital (Contra Costa Medical Center). SP is employed by a multilateral aid agency (United Nations Population Fund) that receives funding from various governments as well as foundation, private sector and individual philanthropic funding. DC is a faculty member at a public university (University of Washington) and is also employed part-time there. SK is a medical student at a public university (Tribhuvan University). AB is a public health student at a public university (University of West England) and works in partnership with a nonprofit organization (Public Health Perspective Nepal) that receives individual philanthropic funding. DM is employed at two academic medical centers (Brigham and Women's Hospital and Boston Children's Hospital) that receive public sector research funding, as well as revenue through private sector fee-for-service medical transactions and private foundation grants. DM is also a faculty member at a private university
(Harvard Medical School) and is a non-voting member on the Board of Directors with Possible, a position for which he receives no compensation. All authors have read and understood BMC Pregnancy and Childhood's policy on declaration of interests, and declare that we have no competing financial interests. The authors do, however, believe strongly that healthcare is a public good, not a private commodity.

\section{Consent for publication}

Not applicable.

\section{Ethics approval and consent to participate}

The Nepal Health Research Council (\#98/2011) and Brigham and Women's Hospital Institutional Review Board (2012P000856) approved the study protocol. We obtained written informed consent, either by signature or thumbprint on a consent form, for the quantitative survey and the qualitative interview.

\section{Author details}

${ }^{1}$ Possible, Bayalpata Hospital, Sanfebagar-10, Achham, Nepal. ${ }^{2}$ Department of Obstetrics and Gynecology, Boston Medical Center, Boston, MA, USA. ${ }^{3}$ Department of Obstetrics and Gynecology, Boston University School of Medicine, Boston, MA, USA. ${ }^{4}$ Department Medicine, Division of Women's Health, Brigham and Women's Hospital, Boston, MA, USA. ${ }^{5}$ Contra Costa Regional Medical Center, Contra Costa Family Medicine Residency, Martinez, CA, USA. ${ }^{6}$ United Nations Population Fund, Kathmandu, Nepal. ${ }^{7}$ Department of Anthropology, University of Washington, Seattle, WA, USA. ${ }^{8}$ Department of Global Health, University of Washington, Seattle, WA, USA. ${ }^{9}$ Henry M. Jackson School of International Studies, University of Washington, Seattle, WA, USA. ${ }^{10}$ Institute of Medicine, Tribhuvan University, Kathmandu, Nepal. ${ }^{11}$ Faculty of Health and Applied Science, University of West England, Bristol, UK. ${ }^{12}$ Public Health Perspective Nepal, Department of Research and Training, Pokhara, Nepal. ${ }^{13}$ Department of Medicine, Division of Global Health Equity, Brigham and Women's Hospital, 75 Francis Street, Boston, MA, USA. ${ }^{14}$ Boston Children's Hospital, Department of Medicine, Division of General Pediatrics, Boston, MA, USA. ${ }^{15}$ Departments of Medicine and Global Health and Social Medicine, Harvard Medical School, Boston, MA, USA.

Received: 14 October 2016 Accepted: 28 February 2017 Published online: 04 March 2017

\section{References}

1. Maternal mortality Fact sheet No. 348. http://www.who.int/mediacentre/ factsheets/fs348/en/. Accessed 23 Nov 2014

2. Lawn J, Lee ACC, Kinney M, Sibley L, Carlo W, Paul V, Pattinson R, Darmstadt G. Two million intrapartum-related stillbirths and neonatal deaths: Where, why, and what can be done? Int J Gynecol Obstet vol. 2009;107:S5-19.

3. Lawn J, Shibuya K, Stein C. No cry at birth: global estimates of intrapartum stillbirths and intrapartum-related neonatal deaths. Bull World Health Organ. 2005:83(6):409.

4. Ministry of Health and Population. Nepal Demographic and Health Survey 2011. Kathmandu: New ERA, ICF International Inc; 2012.

5. Thaddeus S, Maine D. Too far to walk: maternal mortality in context. Soc Sci Med. 1994:38(8):1091-110

6. Gabrysch S, Campbell OM. Still too far to walk: literature review of the determinants of delivery service use. BMC Pregnancy Childbirth. 2009:9:34

7. Witter S, Khadka S, Nath H, Tiwari S. The national free delivery policy in Nepal: early evidence of its effects on health facilities. Health Policy Plan. 2011;26(suppl2):ii84-91.

8. Simkhada B, Simkhada B, Porter M, van Teijlingen E. The role of mothersin-law in antenatal care decision-making in Nepal: a qualitative study. BMC Pregnancy Childbirth. 2010;10:34.

9. Morrison J, Thapa R, Basnet M, Budhathoki B, Tumbahangphe K, Manandhar D, Costello A, Osrin D. Exploring the first delay: a qualitative study of home deliveries in Makwanpur district Nepal. BMC Pregnancy Childbirth. 2014; 14(1):89.

10. Simkhada B, Van Teijlingen ER, Porter M, Simkhada P. Major problems and key issues in maternal health in Nepal. Kathmandu Univ Med J. 2006:4(14) 258-63.

11. Brunson J. Confronting maternal mortality, controlling birth in Nepal: the gendered politics of receiving biomedical care at birth. Soc Sci Med. 2010 71(10):1719-27. 
12. Hurst TE, Semrau K, Patna M, Gawande A, Hirschhorn LR. Demand-side interventions for maternal care: evidence of more use, not better outcomes. BMC Pregnancy Childbirth. 2015;15(1):297.

13. Lee AC, Lawn JE, Cousens S, Vishwajeet K, Osrin D, Bhutta ZA, Wall SN, Nandakumar AK, Syed U, Darmstadt G. Linking families and facilities for care at birth: What works to avert intrapartum-related deaths?(Report). Int J Gynecol Obstet. 2009;107:S65-88.

14. World Health Organization. Monitoring emergency obstetric care: a handbook. Geneva: World Health Organization; 2009.

15. Paxton A, Maine D, Freedman L, Fry D, Lobis S. The evidence for emergency obstetric care. Int J Gynaecol Obstet. 2005;88(2):181.

16. Hofmeyr GJ, Haws RA, Bergström S, Lee ACC, Okong P, Darmstadt GL, Mullany LC, Oo EKS, Lawn JE. Obstetric care in low-resource settings: what, who, and how to overcome challenges to scale up? Int J Gynaecol Obstet. 2009:107 Suppl 1:S21-44. S44.

17. Lawn JE, Kinney M, Lee ACC, Chopra M, Donnay F, Paul VK, Bhutta ZA, Bateman M, Darmstadt GL. Reducing intrapartum-related deaths and disability: can the health system deliver? Int J Gynaecol Obstet. 2009;107 Suppl 1:S123.

18. Rana TG, Chataut BD, Shakya G, Nanda G, Pratt A, Sakai S. Strengthening emergency obstetric care in Nepal: The Women's Right to Life and Health Project (WRLHP). Int J Gynaecol Obstet. 2007;98(3):271-7.

19. Islam MT, Hossain MM, Islam MA, Haque YA. Improvement of coverage and utilization of EmOC services in southwestern Bangladesh. Int J Gynaecol Obstet. 2005;91(3):298-305. discussion 283-294.

20. Institute of Medicine. Study On Utilization of Emergency Obstetric Care (EmOC). Kathmandu: Selected Districts Of Nepal; 2004.

21. Amudhan S, Mani K, Rai SK, S Pandav C, Krishnan A. Effectiveness of demand and supply side interventions in promoting institutional deliveries - a quasi-experimental trial from rural north India. Int J Epidemiol. 2013;42(3):769-80.

22. Maru S, Rajeev S, Pokhrel R, Poudyal A, Mehta P, Bista D, Borgatta L, Maru D. Determinants of institutional birth among women in rural Nepal: a mixedmethods cross-sectional study. BMC Pregnancy Childbirth. 2016;16(1):252.

23. Crabtree BF, Miller William L. Doing qualitative research. Thousand Oaks: Sage Publications; 1999.

24. Sorensen G, Emmons K, Hunt M, Barbeau E, Goldman R, Peterson K, Kuntz K, Stoddard A, Berkman L. Model for incorporating social context in health behavior interventions: applications for cancer prevention for working-class, multiethnic populations. Prev Med vol. 2003;37:188-97.

25. Laurent C, Kouanfack C, Koulla-Shiro S, Nkoué N, Bourgeois A, Calmy A, Lactuock B, Nzeusseu V, Mougnutou R, Peytavin G, et al. Effectiveness and safety of a generic fixed-dose combination of nevirapine, stavudine, and lamivudine in HIV-1-infected adults in Cameroon: open-label multicentre trial. Lancet. 2004;364(9428):29-34.

26. Digital Continuous Household Census. Phase One Summary of Results and Post-Mortem. Achham: Possible; 2015

\section{Submit your next manuscript to BioMed Central and we will help you at every step:}

- We accept pre-submission inquiries

- Our selector tool helps you to find the most relevant journal

- We provide round the clock customer support

- Convenient online submission

- Thorough peer review

- Inclusion in PubMed and all major indexing services

- Maximum visibility for your research

Submit your manuscript at www.biomedcentral.com/submit 